\title{
Characterization of carbon fiber-based strain gauge made by embroidery technology for integration in concrete
}

\author{
Michael Heinrich $^{1}$, Lothar Kroll, ${ }^{1,2}$, Angelika Bauer ${ }^{2}$ \\ ${ }^{1}$ Fraunhofer-Institute for Machine Tools and Forming Technology, Reichenhainer-Str. 88, Germany \\ ${ }^{2}$ Chemnitz University of Technology, Reichenhainer-Str. 31/33, Germany \\ michael.heinrich@iwu.fraunhofer.de
}

\begin{abstract}
Based on approx. 40,000 national bridges of which $39 \%$ obtained in the condition monitoring satisfactory to sufficient according to the report of BMVBS 2013, the demand for an online condition monitoring for the efficient and economic sustainable maintenance and repair measures is there [1]. Thus, cost reductions of up to $50 \%$ are possible with the usage of condition monitoring systems [2]. Plus, the foundation of wind turbines in off-shore areas as well as for supporting concrete elements in high-rise buildings demands for the usage of those systems.

The in the paper presented carbon fiber-based strain gauges aim for the development of a novel condition monitoring system for the integration in supporting concrete elements that take or rather evaluate the dynamic load and thus optimize the maintenance and repair measure intervals. The sensor comprises of a carbon fiber roving that is fixed on a textile base by means of embroidery technology. In the subsequent etching process the base is washed out and the remaining embroidery element is impregnated with epoxy resin. This way an open sensor structure is formed that is resistant to alkaline influences and provides an optimal integration into coarse concrete. First investigations on electro-mechanical and thermal behavior show a great potential for the condition rating of supporting concrete elements.
\end{abstract}

Key words: embroidery, tailored-fiber-placement, strain gauge, concrete, monitoring

\section{Introduction}

The integration of structure monitoring systems (Structural Health Monitoring-SHM) in safetyrelevant buildings, for example bridges, is of great importance as for the age determination and appropriate and targeted reaction to mechanical, thermal, and by the weather caused loads. For this purpose there are already a great number of sensors available on the market that allows the development of intelligent concrete structures with selective characteristics [3-6]. Those SHM-systems, basically based on optical fibers or strain gauges, are reinforcement with great effort to subsequently impregnate them with concrete or are applied to the building structure in a subsequent time-consuming installation process.

Thus, the focus of the present investigation is the development of a textile SHM-system that shows an optimal integration capacity for reinforced concrete structures and records its structural condition. For this purpose, the embroidery technology - that is already used for the manufacturing of textile strain gauges for fiber-reinforced plastic structures [5, 6] - was refined for the development of etching embroidered 3D strain gauge based on carbon fibers [4]. Textile strain gauges of this sort allow the resilient integration of reinforced concrete structures and the registration of metrological mechanical strains for the first time.

\section{Methods: Textile-technological manufacturing of the strain gauge}

The present paper depicts a textiletechnologically manufactured and for the integration of reinforced concrete structures developed strain gauge with an easy handling with regard to its embedding. The embroidered strain gauge comprises of a carbon fiber roving of 67 tex that is in the Tailored-FiberPlacement-Method (TFP) embroidery technologically positioned and fixed on a PVAfleece; cf. Figure 1. In the subsequent process step the usage of etching embroidery disconnects the textile PVA-base, however, the embroidered sensor layout remains intact. The mesh size of the sensor is $10 \mathrm{~mm}$ providing optimal impregnation behavior for concrete with grain sizes smaller than $4 \mathrm{~mm}$. 


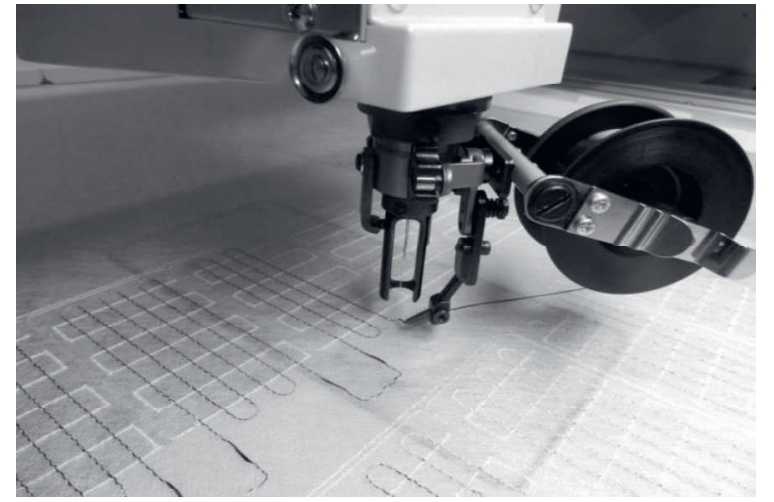

Fig. 1: Tailored-Fiber-Placement for sensor layouts

The frictionally and positively carbon fiber roving bonding was realized by crimped ferrules based on silver paint. For the protection of alkalization inside the concrete, the sensor is impregnated with epoxy resin leading to an electrically isolating and hardening of the sensor structure after the resin has hardened; cf. Figure 2. The produced sensor helps to determine strains, can optimally be integrated into concrete due to its open meander structure and therefore collects directly the from the concrete coming strain.

\section{Embedding of textile-reinforced concrete specimens}

Carrying on, the embroidered sensor was integrated into a concrete matrix and formed to specimen for the four-point-bending test; cf. Figure 3 . The specimen with the dimensions $400 \times 70 \times 10 \mathrm{~mm}^{3}$ has a carbon fiber-based textile-reinforcement with 1,800 tex and is made of fine-grained concrete. The flotation of the etching embroidered strain gauge during the hardening of the concrete results in a relocation from the edge of the specimen towards the neutral fiber. Figure 4 , the cross section, shows the position of the strain gauge is $6.41 \mathrm{~mm}$ away from the surface of the specimen and is located directly next to the neutral fiber. Despite the close proximity to the neutral fiber a strain transmission of the concrete specimen to the etching embroidered strain gauge is expected although the strain will be minor.

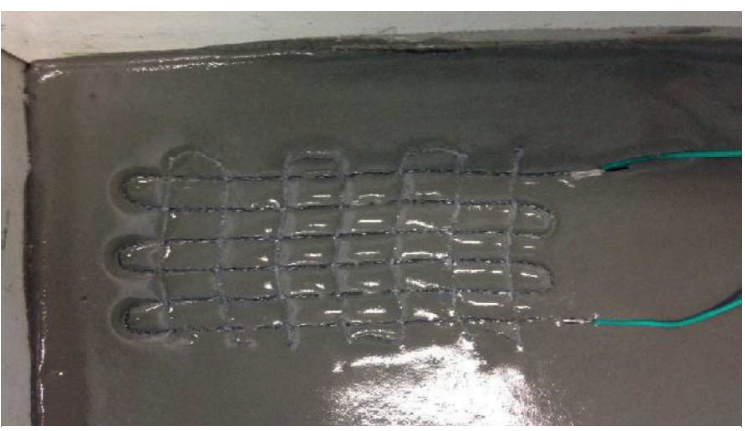

Fig. 3: Embedded strain gauge in concrete specimen

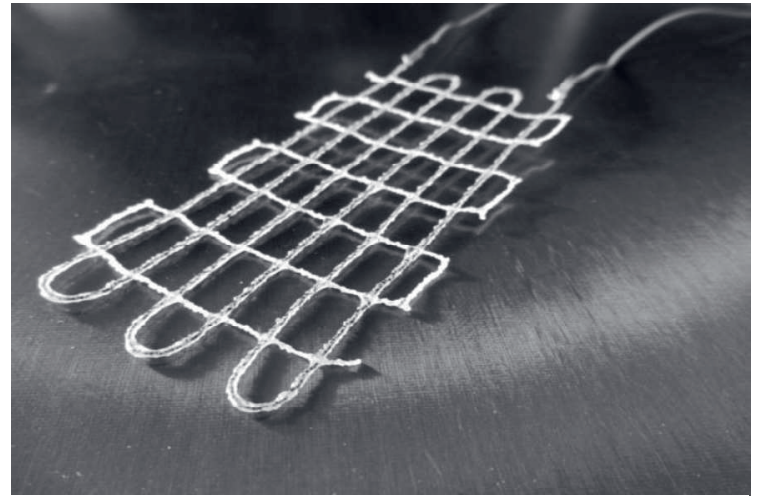

Fig. 2: Embroidered strain gauge made by CF

\section{Test Setup}

In order to allow an electro-mechanical and thermal characterization of the etching embroidered strain gauge the gauge factor or rather temperature behavior was determined.

For the determination of the gauge factor a four-point-bending test was implemented following the VDI norm 2635. Additionally, the thermal influence and humidity on the carbon fiber-based strain gauge was determined in a cyclic thermal load with continuous humidity of $\mathrm{RH}=55 \%$ inside a climatic chamber. During the temperature behavior determination, the temperature-dependent resistance change of the respective sensors was investigated on two concrete specimens with a respectively integrated etching embroidered strain gauge and an applied foil strain gauge. Throughout the testing, the specimens were loaded with four temperature cycles. Each temperature cycles' starting point was $-20^{\circ} \mathrm{C}$ that rose over the period of four hours to $80^{\circ} \mathrm{C}$ and in turn decreased back to $-20^{\circ} \mathrm{C}$ over another period of four hours.

\section{Results: Determination of the gauge factor}

With the aid of the four-point-bending test the relative change of the electric resistance $\Delta R$ of the strain gauges due to the mechanical strain $\varepsilon$ of the concrete specimen was determined. For this purpose the specimen was loaded to the total deflection of $0.5 \mathrm{~mm}$.

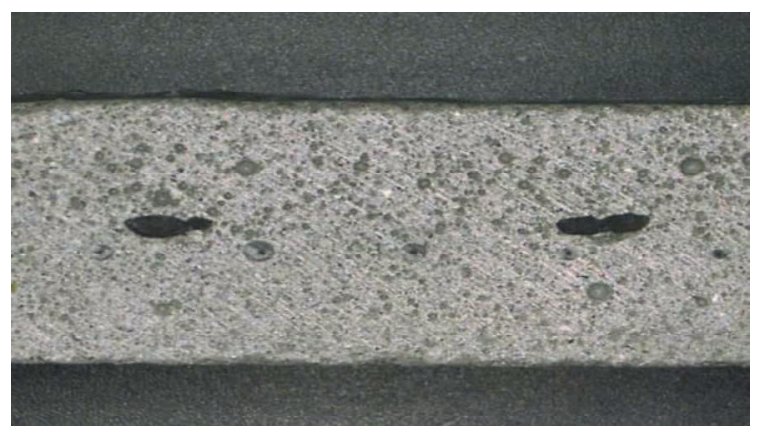

Fig. 4: Cross section embedded strain gauge 
The electro-mechanical proportional factor (gauge factor) was calculated according to the following Equation 1.

$$
\frac{\Delta R}{R_{0}}=k \cdot \varepsilon=k \cdot \frac{\Delta l}{l_{0}} \rightarrow k=\frac{\Delta R}{R_{0} \cdot \varepsilon}
$$

Additionally, microscopic pictures of the concrete specimen cross section identify the real position of the etching embroidered strain gauge; cf. Figure 4. This is absolutely necessary in order to establish the strain in the height of the sensor positioning $h$ during a total deflection of $0.5 \mathrm{~mm}$ of the specimen (in a strain thickness of $10 \mathrm{~mm}$ ). The adjustment of the strain was calculated according to the equation

$$
\varepsilon_{c o r}=\frac{\varepsilon}{h}(h+2 \cdot t) .
$$

The results of the four-point-bending test show a gauge factor of $1.7 \pm 7 \%$ for the carbon fiberbased strain gauges.

\section{Determination of the temperature behavior}

The temperature changes affecting the etching embroidered strain gauge result in an electromechanical change of resistance causing an apparent strain $\varepsilon_{\mathrm{s}}$ in the measuring signal. This strain can either be compensated by using a half or full bridge circuit or by subtracting the mechanically unloaded temperature behavior of the measured sensor signal afterwards. The apparent strain is significantly dependent on the following factors:

- Thermal coefficient $\alpha_{R}(T)$ of the specific electric resistance,

- Thermal expansion coefficient of the carbon fiber $\alpha_{C}(T)$

- Thermal expansion coefficient of the concrete $\alpha_{B}(T)$ and

- k-factor of the etching embroidered strain gauge.

Based on the factors described above the apparent strain is calculated from Equation 3:

$$
\varepsilon_{\mathrm{s}}=\Delta \mathrm{T} \cdot\left(\alpha_{\mathrm{B}}-\alpha_{\mathrm{C}}+\frac{\alpha_{\mathrm{R}}}{\mathrm{k}}\right)
$$

With regard to the temperature behavior analysis inside the climatic chamber where an apparent strain of $225 \mu \mathrm{m} \cdot \mathrm{m}^{-1} \cdot \mathrm{K}^{-1}$ occurred in the concrete specimen (cf. Figure 5 ) and by using $\alpha_{C}(T)=-0.1 \cdot 10^{-6} \mathrm{~K}^{-1}, \alpha_{B}(T)=8.94 \cdot 10^{-6} \mathrm{~K}^{-1}$ und $\mathrm{k}=1.7$ the specific electrical resistance $\alpha_{R}(T)=382 \cdot 10^{-6} \mathrm{~K}^{-1}$ can be calculated with Equation 3. The result is a multiple of the thermal expansion coefficients of the single materials and therefore significantly dominates the thermal influence on the measuring signal.

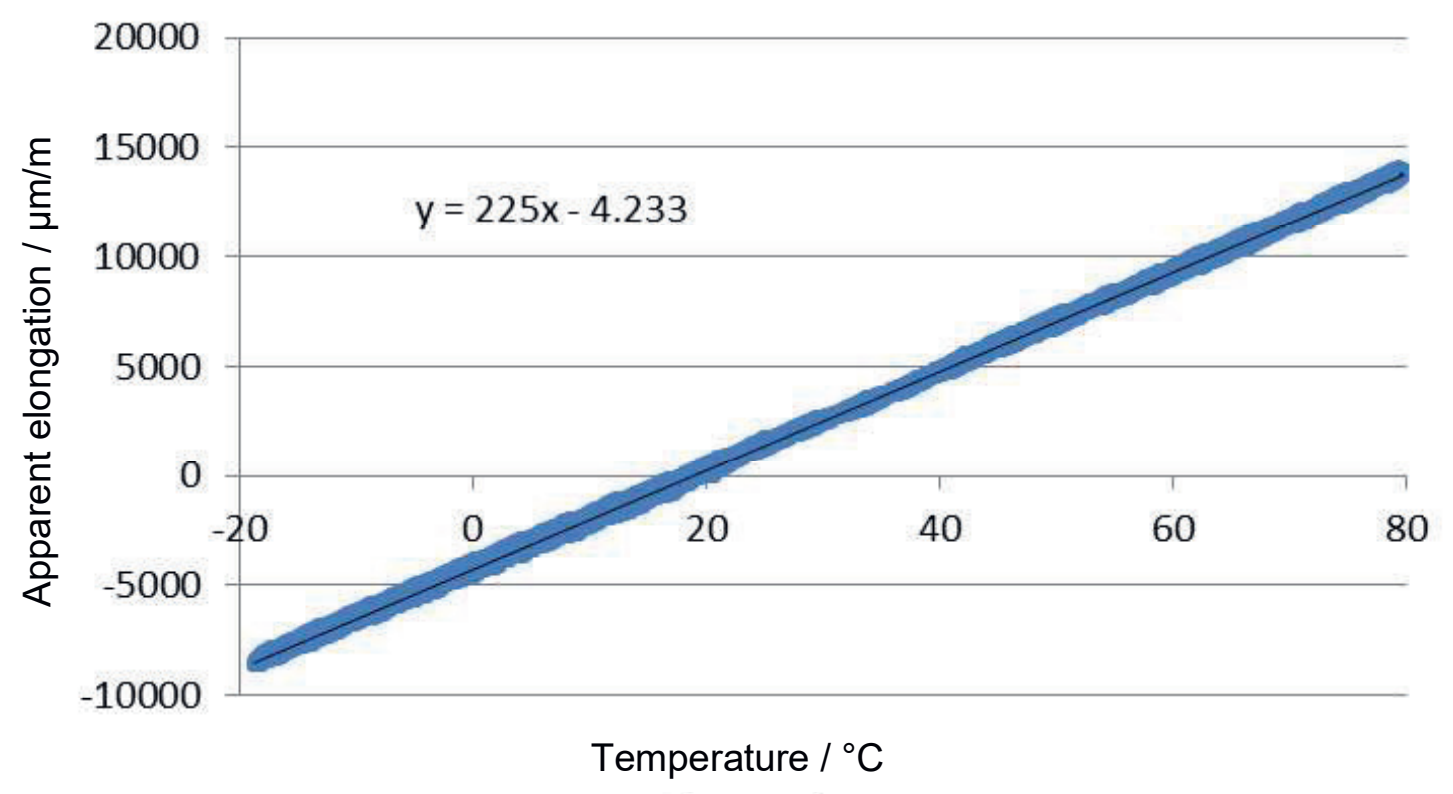

Fig. 4: Temperature range of the unloaded strain gauge 


\section{Summary}

Based on the first tests for the determination of the electro-mechanical proportionality of carbon fiber-based strain gauges a gauge factor of $1.7 \pm 7 \%$ at room temperature was determined. Furthermore, temperature behavior analysis showed that the etching embroidered strain gauge has an electrical resistance of $\alpha_{R}(T)=$ $382 \cdot 10^{-6} \mathrm{~K}^{-1}$ and is therefore strongly dependent on temperature. As the sensor design expects to have a high cross-sensitivity and the temperature and humidity do have a significant influence on the signal behavior, further investigations are necessary.

Additional investigation of the integration capacity showed that the open sensor structure leads to a complete impregnation of the carbon fiber with concrete. This results in a direct transmission of mechanical strains within the structure to the textile strain gauge.

The results show that the sensor development and its metrological signal detection allow for a strong application in the building industry. Furthermore, the development offers an enormous potential of integration, corrosion resistance, and imperfection behavior in comparison to on the market already existing sensor solutions.

\section{Acknowledgements}

This work was performed within the Federal Cluster of Excellence EXC 1075 "MERGE Technologies for Multifunctional Lightweight Structures" and supported by the German Research Foundation (DFG). Financial support is gratefully acknowledged.

\section{References}

[1] BMVBS: Strategie zur Ertüchtigung der Straßenbrücken im Bestand der Bundesfernstraßen. Berlin, 22. Mai 2013

[2] Thöns, S., 2013. Autobahnbrücken als intelligente Bauwerke, BAM Federal Institute for Materials Research and Testing, Berlin [Germany], NDT.net Issue: 2013-05

[3] Gelbrich, S.; Lange, R.; Ulbricht, J.; Putsche, M., 2013. Sensor for the determination of residual moisture in cement screed constructions. In: Ilki, A.; Motavalli, M.; Goksu, C.; Havranek, B.: Proceedings of SMAR 2013: Second Conference on Smart Monitoring, Assessment and Rehabilitation of Civil Structures. Istanbul, p. 38. ISBN 9783-033-04055-7.
[4] Kroll, L. et al.: Novel Strain Gauge Sensor made by Embroidery Technology for Integration in Concrete. SMAR 2015 - Third Conference on Smart Monitoring, Turkey, 2015

[5] Kroll, L.; Gelbrich, S.; Ulbricht, J.; Elsner, H., 2009. Material integrated textile sensors in lightweight structures. 4th International Conference on Structural Health Monitoring on Intelligent Infrastructure (SHMII-4). Zürich.

[6] Ulbricht, J.; Gelbrich, S.; Kroll, L.; Elsner, H.; Elflein, F., 2011. Material integrated textile sensors in lightweight structures for applications in civil engineering. In: Motavalli, M.; Havranek, B.; Saqan, E.: Proceedings of SMAR 2011: First Middle East Conference on Smart Monitoring, Assessment and Rehabilitation of Civil Structures. Dubai, S. 48. ISBN 978-3905594-58-4. 